\title{
Three-dimensional numerical modelling for successful design of steep slopes at the Kanmantoo copper mine
}

\author{
DS Lucas Mining One Pty Ltd, Australia
}

A Vakili Mining One Pty Ltd, Australia

BJ Hutchison Hillgrove Resources Limited, Australia

\begin{abstract}
Hillgrove Resources Limited (HGO) operated the Kanmantoo copper open pit mine in South Australia from 2010, until its successful completion in May 2019. The mine was a drill and blast, truck and shovel operation, and included the Kavanagh pit which was completed in 2014 at a depth of $240 \mathrm{~m}$. It was extended and deepened to create the Giant Pit, which was recently completed at more than $360 \mathrm{~m}$ deep. Structures control the stability of all pit walls, but the west wall is dominated by a set of widely spaced but extensive joints that dip toward the east, denoted the J1 joint set, and it proved to be the most challenging to design and to manage hazards.

Lessons learned in mining of Kavanagh pit led to the west wall of Giant Pit being designed with steeper batters and inter-ramp slope angles, which are undercut by widely spaced, highly persistent, east-dipping joints (set J1). There were concerns about the possibility of large-scale, deep-seated failure due to sliding on J1 structures and through intact rock. The depth, steep walls and confined lower benches also raised concerns about the potential influence of mining-induced stresses on larger-scale stability.

Several phases of three-dimensional numerical modelling were conducted to assess the larger-scale stability. Modelling indicated that the steeper design could be achieved with an acceptable Factor of Safety against larger-scale instability, but that crest failures and rockfalls should be expected. In early 2018, when the Giant Pit was two thirds completed, HGO identified some increased movement that had been developing gradually for some time. Modelling was carried out using FLAC3D with structures represented as explicit discontinuities, generated by means of a discrete fracture network (DFN), and the rock mass represented as a finite difference mesh. The improved unified constitutive model was used in FLAC3D analysis as this model offers a more reliable prediction of the rock mass behaviour in higher stress conditions. A back-analysis model showed a good match to the observed magnitude and distribution of displacement, relationship to the structures, and the interpreted mechanism of the movement. The forward analysis showed that the Giant Pit could be completed with an acceptable Factor of Safety against larger-scale wall failure. The good ongoing agreement between the modelled and observed displacements provided confidence in the forward predictive abilities of the modelling method.
\end{abstract}

Successful completion of the Giant Pit essentially verified the modelling predictions that the large-scale Factor of Safety would exceed the mine's design criterion of 1.30, and that mining-induced stress due to the three-dimensional shape of the pit would not induce stress-driven failure. The three-dimensional shape and complex structures could not have been modelled as successfully using more traditional slope stability analysis methods.

Keywords: slope stability, slope design, numerical modelling, steep mining

\section{Introduction}

Hillgrove Resources Limited (HGO) owns the Kanmantoo copper mine, located approximately $55 \mathrm{~km}$ southeast of Adelaide, South Australia. 
Mining in the Kanmantoo copper mine area dates back to the 1860 s to 1880 s when Cornish miners carried out mainly narrow vein underground mining in the upper oxidised zone. In the 1970s, the original open cut Kanmantoo copper mine was developed by a previous owner and an underground development was established. Mining ceased in 1976 due to unfavourable copper prices.

HGO purchased the exploration leases in 2004, and eventually gained a mining lease in 2011 . The mine operated in several small open cut operations; including the Spitfire Pit, which excavated through old underground workings, and the Kavanagh Pit, which was developed around the old Kanmantoo Pit. The Kavanagh Pit was completed in 2014 at a depth of $240 \mathrm{~m}$.

Mining operations culminated with the Giant Pit, which extended and deepened the former Kavanagh Pit and also encompassed the Spitfire Pit. The Giant Pit became not only the largest and deepest pit at the Kanmantoo mine, but was also successfully completed with the steepest slope designs. Mining of the Kavanagh pit and the adjacent Nugent pit (Figure 1) provided HGO with a valuable understanding of the geotechnical factors that control slope stability. To improve berm retention a series of shear pin trials were undertaken in Nugent pit. That knowledge was used to design and successfully implement the Giant Pit, in the same rock types and structural conditions, but with a steeper and more cost-effective design, refer to Hutchison et al. 2017, than had been thought possible in the earlier stages of HGO's mining operations. The Giant Pit extended to more than $360 \mathrm{~m}$ deep, with steeper batters and inter-ramp angles (Figure 2).

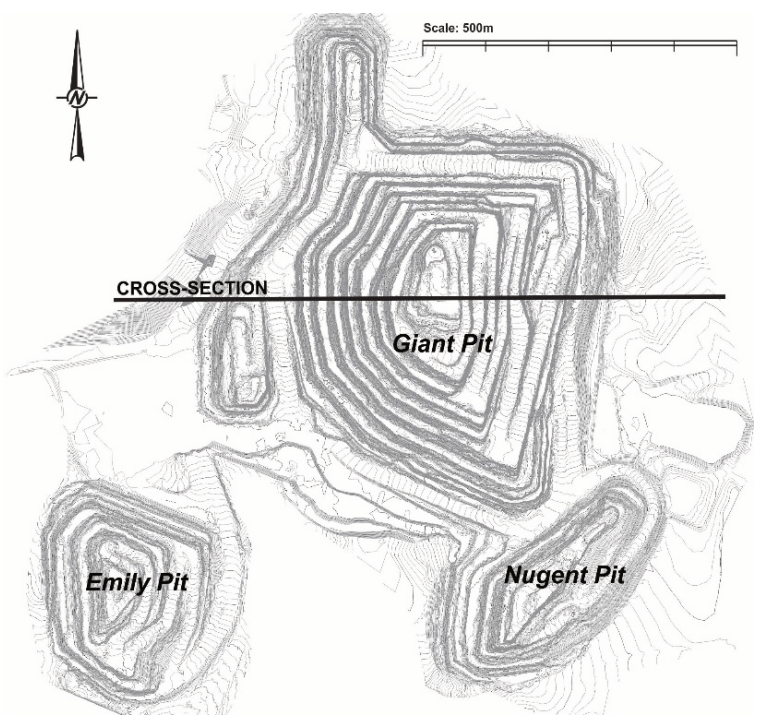

Figure 1 Plan of Kanmantoo pits (see Figure 2 for cross-section)

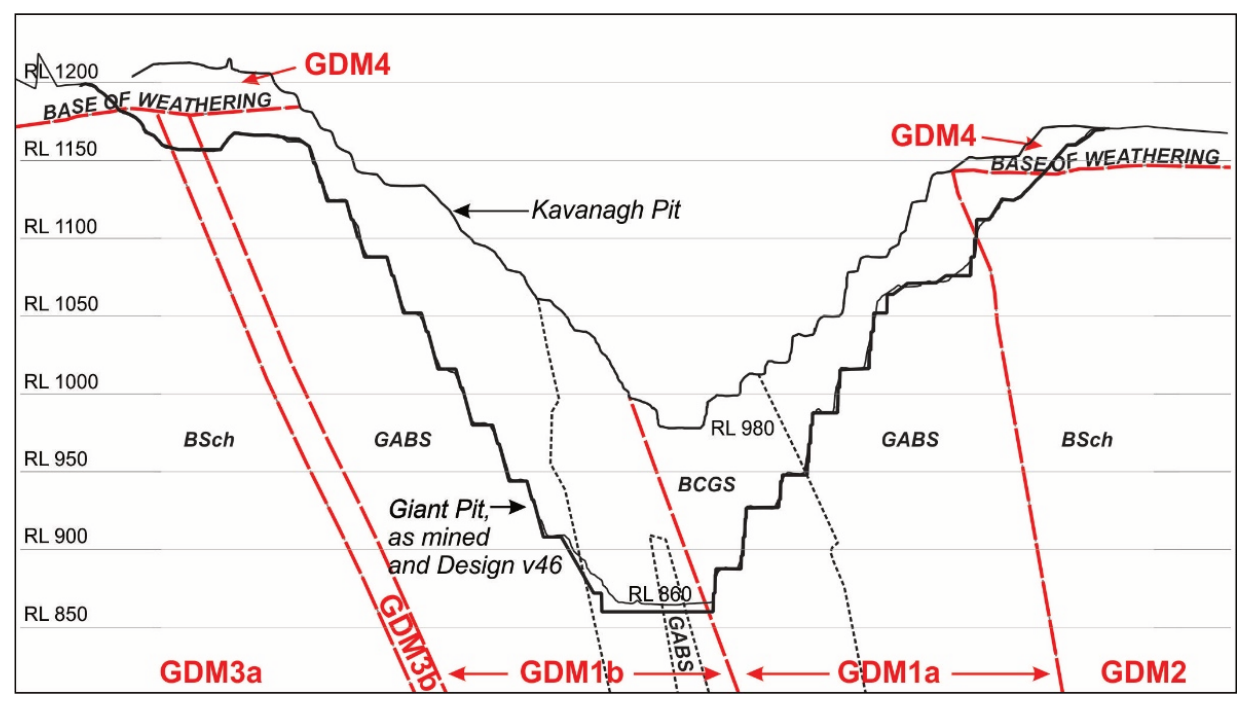

Figure 2 Cross-section of Giant Pit, geology, and geotechnical domains (in red) (see Figure 1 for section location) 
The Kanmantoo copper mine is developed in high-strength rocks, which limited the potential for rock mass failures and provided opportunities to develop steep slope designs. Structures control the stability of all pit walls in the Giant Pit. The west wall is dominated by a set of widely spaced but highly persistent joints that dip toward the east, which is denoted the $\mathrm{J} 1$ joint set. In transitioning from the Kavanagh to the Giant Pit, as rockfall controls were improved, HGO pursued steeper batters and inter-ramp slope angles in the west wall. The J1 joints undercut the west wall batters. Shear pinning and rockfall barrier methods were used to limit crest losses and control rockfall hazards. However, the unprecedented depth of the Giant Pit, the steep walls, and the confined lower benches led to concerns about the potential influence of mining-induced stresses on larger-scale stability. In particular, there were concerns about whether a larger-scale failure could develop on a combination of $\mathrm{J} 1$ and foliation joints and/or through the rock mass.

HGO favoured three-dimensional (3D) numerical modelling as a preferred method of investigating the larger-scale stability. A significant benefit of this type of modelling is its ability to show progressive onset of complex stress-driven mechanisms and potential precursors to failure, even when the design is far from failure. In addition, the method is well suited to modelling the shape of the pit, which is three-dimensionally confined with a convex corner in the west wall.

HGO first commissioned three-dimensional numerical modelling of the Giant Pit in 2015, with a focus on the west wall (Sainsbury et al. 2016). Further modelling was completed in 2017 following concerns about the stability of the east wall since 2016. Modelling in 2018 focused on increased displacement of the west wall. Further modelling was completed in 2019 near the end of open cut mining, and focused on long-term stability pending future uses of the Giant Pit, including for access to a proposed underground mine.

This paper describes the outcomes of the various phases of numerical modelling with a focus on the west wall observed versus modelled behaviour.

\section{$2 \quad$ Geotechnical setting}

\subsection{Geology}

The mine is located on the south-eastern edge of the Adelaide Fold Belt, and is hosted within the Cambrian age Kanmantoo Group, a 7-8 km thick sequence of marine deposited meta-sediments which has been metamorphosed to schist of amphibolite facies.

The mine lies within an approximately north-south striking garnet-rich alteration zone of the Kanmantoo Syncline. The region has a complex structural history with several phases of deformation, and thrust faulting is known to have occurred in the region. Regional faults include the Bremer and Nairne Faults, which trend approximately north-south and lie several kilometres to the east and west. No major regional faults occur within or near the deposit, although some persistent shear structures have been identified.

Within the Giant Pit, the schists occur in a north-south striking, east-dipping sequence with foliation dipping east between $70^{\circ}$ and $80^{\circ}$. Figure 2 shows an east-west cross-section of the geology, looking toward the north. The main rock types are shown in Figure 2, and are:

- Biotite schist (BSch) is the host rock that bounds the other rock units on the eastern and western margins. It is light grey, fine grained, matt textured and highly foliated, and is a softer, more ductile and more readily weathered rock than those listed below.

- Garnet andalusite biotite schist (GABS) is grey-green and foliated. It consists of large (5 to $10 \mathrm{~mm}$ ) porphyroblastic andalusite crystals making up an average $8 \%$ of the rock, set in a coarse-grained schistose matrix of predominantly biotite and quartz, with almandine garnet and minor chlorite.

- Biotite garnet chlorite schist (BCGS) is poorly foliated and fine grained. It is gradational with the GABS and is thought to be a metamorphic chloritisation and alteration by mineral replacement of the latter rock type. The lenticular orebodies are contained within the BCGS. 
The weathered horizon in the GABS is very shallow. Slight weathering (iron staining of discontinuities) continues to be seen throughout the depth of the pit, but this has not affected the rock mass strength to any significant degree. To the west and east of Giant Pit is the BSch; which is extremely to distinctly weathered. The depth of weathering is variable but is generally less than $36 \mathrm{~m}$, extending locally deeper along some zones bounded by foliation.

\subsection{Geotechnical domains}

HGO defined a geotechnical domain model based upon these lithologies and sub-divisions (GDM1a/b) and a transition (GDM3b) based upon observations (Figure 2). Characteristics of the geotechnical domains are described in Table 1.

Table 1 Geotechnical domains

\begin{tabular}{|c|c|c|c|}
\hline Domain & Lithologies & Distribution & Rock mass characteristics \\
\hline GDM1a & GABS, BCGS & $\begin{array}{l}\text { Central and eastern Giant } \\
\text { Pit }\end{array}$ & $\begin{array}{l}\text { Massive, geological strength index } \\
\text { (GSI) = 80-90. Strong, brittle failure } \\
\text { characteristics }\end{array}$ \\
\hline GDM1b & GABS, BCGS & Western part of Giant Pit & $\begin{array}{l}\text { Blocky to massive, GSI }=60-85 \text {. } \\
\text { Strong, brittle failure characteristics. } \\
\text { More slabby that GDM1a due to } \\
\text { extensive foliation plane joints (F1) }\end{array}$ \\
\hline GDM2 & BSch & $\begin{array}{l}\text { Upper east wall of Giant } \\
\text { Pit, and east of GDM1b }\end{array}$ & $\begin{array}{l}\text { Seamy, GSI = 30-60. Ductile failure } \\
\text { characteristics }\end{array}$ \\
\hline GDM3a & GABS, BSch & $\begin{array}{l}\text { Upper west wall of Giant } \\
\text { Pit, and west of GDM1a }\end{array}$ & $\begin{array}{l}\text { Blocky to seamy, GSI = } 35-65 \text {. Ductile } \\
\text { and brittle failure characteristics }\end{array}$ \\
\hline GDM3b & $\begin{array}{l}\text { Predominantly BSch, } \\
\text { with lenses of GABS \& } \\
\text { BCGS }\end{array}$ & $\begin{array}{l}\text { Transition zone between } \\
\text { GDM3a and GDM1a }\end{array}$ & $\begin{array}{l}\text { Blocky to seamy, GSI }=35-65 \text {. Ductile } \\
\text { and brittle failure characteristics }\end{array}$ \\
\hline GDM4 & $\begin{array}{l}\text { Weathered rock and } \\
\text { soil }\end{array}$ & $\begin{array}{l}\text { Thin across GDM1a/1b, } \\
\text { up to } 36 \mathrm{~m} \text { deep across } \\
\text { GDM } 2 \text { and GDM3a/3b }\end{array}$ & $\begin{array}{l}\text { Variably weathered rock and clayey } \\
\text { soils }\end{array}$ \\
\hline
\end{tabular}

\subsection{Structures}

Rock mass structures at Kanmantoo mine are well documented from work by Coffey Mining (2007), Pando Australia (2012), Rocktest Consulting (2013), and HGO's ongoing mapping using laser scanning. Figure 3 shows a stereonet of recent structural mapping by HGO, which was analysed using Rocscience Dips software to derive the range of orientations summarised in Table 2. These focus on the structure sets that influence the stability of the west wall: the east-dipping foliation (F1); extensive, east-dipping joints (J1), steeper east-dipping joints (J4), and steeply north-dipping joints that provide lateral release for the other sets (J2). 


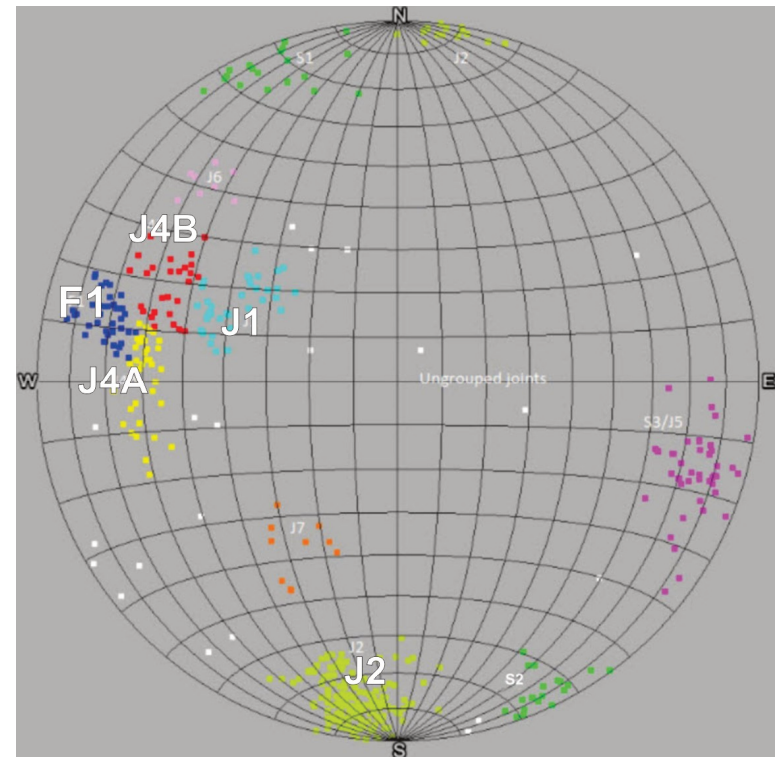

Figure 3 Stereonet of structural data from HGO's recent mapping

Table 2 Dips and dip directions of key structural sets

\begin{tabular}{lll}
\hline Structure set & $\begin{array}{l}\text { Average dip } \\
( \pm 1,2 \text { standard deviations })\end{array}$ & $\begin{array}{l}\text { Average dip direction } \\
( \pm 1,2 \text { standard deviations })\end{array}$ \\
\hline J1 & $39^{\circ}\left( \pm 8^{\circ}, 13^{\circ}\right)$ & $125^{\circ}\left( \pm 8^{\circ}, 13^{\circ}\right)$ \\
J2 & $77^{\circ}\left( \pm 10^{\circ}, 16^{\circ}\right)$ & $009^{\circ}\left( \pm 10^{\circ}, 16^{\circ}\right)$ \\
F1 & $74^{\circ}\left( \pm 7^{\circ}, 11^{\circ}\right)$ & $103^{\circ}\left( \pm 7^{\circ}, 11^{\circ}\right)$ \\
J4, GDM1b only & $64^{\circ}\left( \pm 6^{\circ}\right)$, range $48-71^{\circ}$ & $092^{\circ}\left( \pm 6^{\circ}\right)$, range 082-129 \\
\hline
\end{tabular}

\section{$2.4 \quad$ Groundwater}

The regional groundwater setting was investigated by Sinclair Knight Merz Pty Ltd (Jacobs) (2014). Groundwater is hosted in a fractured rock aquifer in which water is contained within discrete fractures within crystalline rock of low intrinsic permeability. Groundwater flows generally from the north-west to the southeast. The Giant Pit acts as the major groundwater sink. Piezometers surrounding the pit indicate that the phreatic surface is very steep behind the pit walls.

Groundwater seepages in the north-west of Giant Pit indicated that the regional groundwater was intersected at a shallow depth, but seepages into the pit were typically low. Groundwater has been observed seeping from dilated J1 joints in the lower walls, which is expected to have locally reduced the pore pressure near pit walls. In addition, HGO drilled horizontal drains $50 \mathrm{~m}$ deep in all walls of the Giant Pit down to RL 940 . They were planned at spacings of $25 \mathrm{~m}$ horizontal and $12 \mathrm{~m}$ vertical.

Fracture aperture and corresponding higher hydraulic conductivity are expected to be inversely proportional to depth, both below ground and into Giant Pit walls, due to greater lithostatic stress at depth. Weathered rock at shallow depths is likely to have a reduced permeability due to weathering products infilling fractures, which may be partly counteracted by lower lithostatic stress and consequent dilation of fractures.

Groundwater was represented in the model as a phreatic surface, regionally at RL 1148 , and intersecting each bench toe within the Giant Pit, which is considered to be fairly conservative representation.

\section{$2.5 \quad$ In situ stress}

No in situ stress data is available for the Kanmantoo mine or the surrounding region. 
Based upon a summary of principal stress trends for the Gawler-Curnamona stress province in south-eastern South Australia (Lee et al. 2008), the in situ stress was modelled as lithostatic (based on the weight of the rock above), and the major principal stress oriented WNW-ESE with magnitude 1.83 times the vertical stress.

\section{Slope stability controls}

Pit wall stability in the Giant Pit is controlled by the structure sets described above with each wall experiencing particular interactions with structures. Sainsbury et al. (2016) described the stability controls of each wall in some detail. Giant Pit was completed with relatively minor stability issues due to structures in the south, east and north walls. The focus of this paper is on the west wall stability, where J 1 and J4 structures caused numerous rockfalls and batter scale failures, and proved to be the greatest challenge in achieving the steep slope design.

HGO uses shear pins as a method of supporting bench crests against sliding on J1 joints. These are described in detail by Hutchison et al. 2020. Figure 4 shows an example of batters undercut by J1 joints, with crest losses, rockfalls, and crests supported by shear pins. The extensive J1 joints can be seen throughout the area.

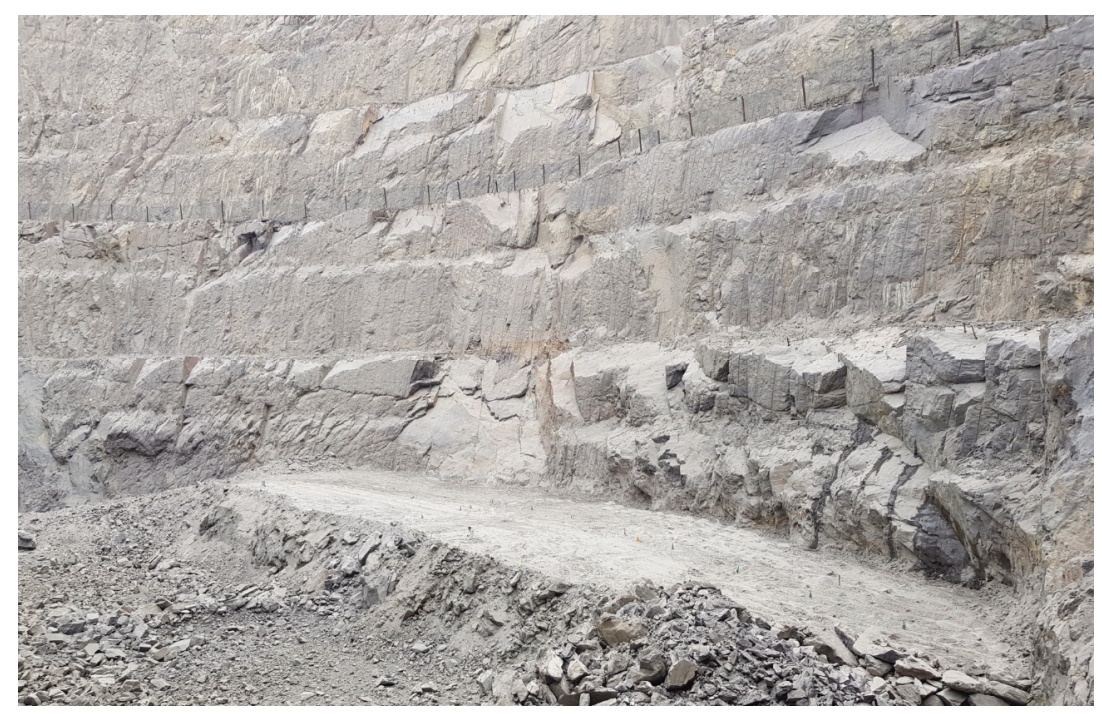

Figure 4 Example of west wall, mined to RL 908, batters undercut by J1 joints, with rockfalls and batter failure, and supported by shear pins (right of photograph)

\section{$4 \quad$ Numerical modelling methodology}

\subsection{Rock mass constitutive model}

The improved unified constitutive model (IUCM) method was used for this study. IUCM is described in detail by Vakili (2016). This model gathers the most notable and widely accepted previous research work in the area of rock mechanics and integrates it into a unified constitutive model that can provide a more reliable prediction of the stress-strain relationships in a continuum model. Several back-analyses and validation studies completed during the development of this model confirmed its applicability for a broad range of ground conditions, from massive brittle hard rock to heavily jointed and ductile rock, and anisotropic rock.

The IUCM was developed with the intention to provide a unified material model that has the complexities required for application to a wide range of geotechnical applications and conditions yet is simple enough to be used by most geotechnical practitioners.

The key components and features of the IUCM are:

- For the peak failure envelope of the rock matrix, the IUCM uses the generalised Hoek-Brown failure criterion, and determines the instantaneous Mohr-Coulomb parameters (cohesion $c$ and friction $\phi$ ) at each level of confining stress, at $\pm 0.001 \mathrm{MPa}$ tolerance. The conversion to Mohr-Coulomb 
parameters provides several advantages, including a simple mathematical representation, widespread acceptance and use in geotechnical numerical modelling programs, a clear meaning of the material parameters, and simpler interpretation of results in terms of those parameters.

- Calculation of instantaneous Mohr-Coulomb parameters is carried out for small stress increments, using a process described in Vakili (2016), to avoid errors that may arise at extremely low or high stresses when fitting linear or multi-linear Mohr-Coulomb criteria to Hoek-Brown curves.

- The initial inputs are the unconfined compressive strength (UCS or $\sigma_{c}$ ) of the intact rock, the geological strength index (GSI) of the rock mass, and the Hoek-Brown intact rock constant $\mathrm{m}_{\mathrm{i}}$. The Hoek-Brown disturbance factor (D) is not explicitly applied (unless assigned specifically by the user, which was not done in this case). Instead, the rock mass is represented as initially undisturbed rock $(D=0)$, and the IUCM models rock mass relaxation explicitly through strain and modulus softening and stress updates. These instantaneous parameters are updated in real-time as the model runs and as new phases of confinement are formed from nearby damage or geometrical changes.

- For the residual state of the rock matrix, the model assigns a linear Mohr-Coulomb envelope. Properties of completely broken and crushed rock are applied.

- The critical strain in this model is chosen based on equations suggested by Lorig \& Varona (2013). In this method, critical strain values are determined based on model zone size and the GSI value of each rock unit.

- The dilation angle is determined using the relationship proposed by Alejano \& Alonso (2005). This relationship gives an estimate of the peak dilation angle based on confinement, friction angle, and the uniaxial compressive strength of the rock $\left(\sigma_{\mathrm{cm}}\right)$. The dependency of this relationship on confinement levels results in higher dilation angles at lower confinements, and lower dilation angles at higher confinements. Additionally, it causes a degradation of dilation angle with increasing damage, and ultimately the dilation angle is reduced to zero when the maximum porosity of $40 \%$ is reached in the model zones. This behaviour is similar to that observed in laboratory rock testing results.

- The IUCM accounts for the confinement dependency of the rock damage process at various stages from peak to residual. Confinement dependency is an important factor controlling rock damage and seismicity in high stress conditions; however, it is largely ignored in most conventional constitutive models. In the IUCM, at low confinement levels, the linear nature of the residual envelope replicates cohesion and friction softening. At high confinement levels, it replicates cohesion softening and friction hardening.

- Most conventional constitutive models assume a constant modulus of elasticity for the rock mass, irrespective of its damage state. In real-life situations, when rock undergoes failure and continuous loading, more voids are generated within the rock mass. The rock mass porosity is subsequently increased. The greater the porosity in the rock mass, the lower its elastic modulus. The drop in rock mass modulus can significantly affect the redistribution of stresses around a failed area and the subsequent phases of induced confinement. The IUCM uses a relationship to update the elastic modulus values according to new porosity levels. The porosity is calculated using the model volumetric strain outputs.

- The strength anisotropy in the IUCM is explicitly included through a ubiquitous joint model, which accounts for both rock matrix strength and the lower strength associated with the existence of an anisotropy plane. For anisotropic rocks, the model uses two non-linear Hoek-Brown failure envelopes. One envelope defines the maximum strength and is related to the rock matrix strength. The other defines the minimum strength associated with the anisotropy plane.

- This constitutive model is implemented in the explicit finite difference code FLAC3D (currently for version 5.0) and therefore uses a time-stepping solution for calculations. As a result, progressive 
and time-dependent failures can be replicated in this model by updating the material properties as a function of new confinement and strain levels.

\subsection{Model geometry}

The FLAC3D model was constructed with a zone size approximately $7 \mathrm{~m}$ in the area of interest, to simulate the geotechnical domains shown in Figure 3 using wireframes provided by HGO. To accurately simulate the stress path of the final pit slope, the model was excavated in $50 \mathrm{~m}$ horizontal slices. At each excavation step, two calculation steps are taken as recommended by Read \& Stacey (2009). In the first step, the model is run elastically to remove any initial transient or inertial effects caused by sudden removal of a large amount of material. In the second step, the model is run allowing plastic behaviour to develop.

\subsection{Representation of structures}

Rock mass structures were represented in the FLAC3D model as explicit structures, which are incorporated into the finite element mesh along with the pit geometry, mining stages, and geotechnical domains. Structures were generated as a discrete fracture network (DFN).

Structures cannot be included in a numerical model at actual locations and spacings that occur, because the model would be too complex. Instead, locations are generated at random, and spacings need to be adjusted so that there is an accurate representation of the relative structure frequency of each set. When structures are represented with broader spacings than occur, the spacings of sets relative to each other are consistent, and the relative occurrence of structures of each set is modelled accurately at a larger-scale. Hence, rock mass behaviour at a larger-scale will be appropriately represented, although stability at a bench scale is not expected to be representative. The focus of a FLAC3D model of this type is on larger-scale stability, for which this approach is considered to be reasonable.

Generating DFNs that are representative of the rock mass fracture network and associated real-life structural data, however, is challenging. It requires a thorough understanding of the critical input parameters used to generate them. In this study, a guideline for the selection of key DFN parameters proposed by Vakili et al. (2014 a) was used to generate the DFNs.

Computational limitations mean that the DFN is limited to a maximum of approximately 5,000 structures. In order to better represent rock mass behaviour in the key areas, structure density was greater within $20 \mathrm{~m}$ of pit walls and was reduced between $20 \mathrm{~m}$ and $100 \mathrm{~m}$ from pit walls, and no structures were included in the GDM2 and GDM3b domains.

Figure $5 a$ shows the DFN representations of the rock mass structures, and Figure $5 b$ shows a cross-section through the west wall and the DFN representation of structures. HGO also identified two major structures in the west wall that formed potential release planes. The southern structure is nearly vertical and strikes south-southeast to north-northwest. The northern structure dips approximately $65^{\circ}$ toward approximately north. These were also included in the FLAC3D model as explicit structures and are shown in Figure $5 c$.

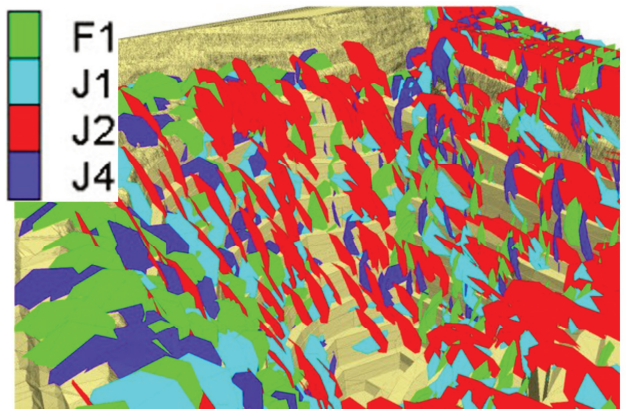

(a)

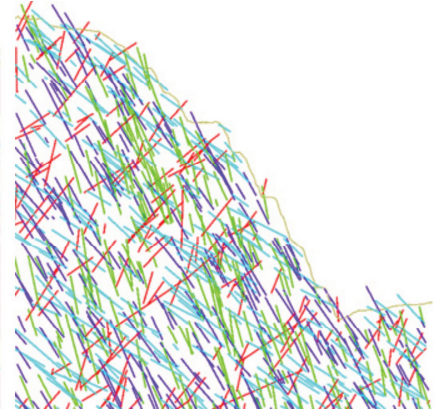

(b)

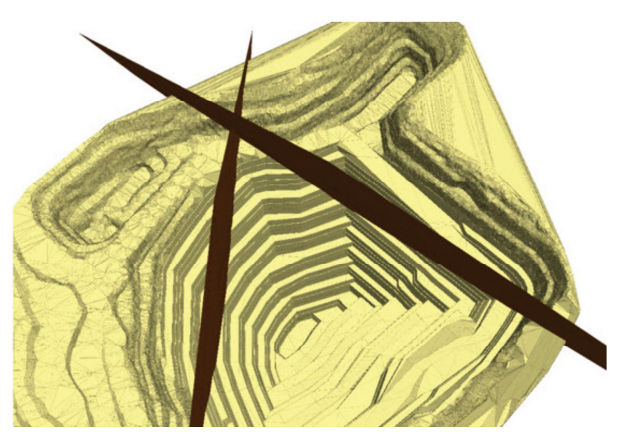

(c)

Figure 5 (a) DFN representation of west wall joint sets; (b) Cross-section through west wall and DFN; (c) Two major structures 


\subsection{Material parameters}

Rock mass parameters were derived from HGO's database of rock testing, which comprises 82 UCS tests and 21 tensile tests. UCS tests were assessed in terms of their strength versus angle of applied load relative to foliation, for anisotropic domains, to determine anisotropic parameters. Mean values were derived and used for the modelling. The IUCM includes an anisotropy factor, which is the ratio of the uniaxial compressive strength, $\sigma_{c}$, across and along foliation; i.e. the ratio of $\sigma_{c \max }$ to $\sigma_{\mathrm{cmin}}$.

The Hoek-Brown intact rock parameter $\left(m_{i}\right)$ was assessed from the ratio of UCS to tensile strength tests, which was 13 and 15 for the GABS and BCGS units, respectively. The limited number of tests, and the lack of Hoek triaxial tests on intact rock, raised concerns about over-estimated $\mathrm{m}_{\mathrm{i}}$. Considering typical values of schist (12 \pm 3$)$, a slightly conservative value of 10 was adopted for $m_{\text {imax }}$, the mi value for failure through intact rock (across foliation). The IUCM also requires an input value of $m_{\text {imin }}$ representing the mi parameter for shearing along foliation in anisotropic rocks. This was selected as half the $m_{\text {imax }}$ value, based on experience for schists of low to medium anisotropy (review of past literature by Vakili et al. 2014b).

Table 3 Improved unified constitutive model (Vakili 2016) rock mass parameters applicable to west wall

\begin{tabular}{llllllllll}
\hline Domain & $\begin{array}{l}\text { Density } \\
\left(\mathbf{t} / \mathbf{m}^{3}\right)\end{array}$ & $\begin{array}{l}\mathbf{E i}^{1} \\
(\mathbf{G P a})\end{array}$ & $\begin{array}{l}\mathbf{S i g c i}^{2} \\
(\mathbf{M P a})\end{array}$ & $\begin{array}{l}\mathbf{M i} \\
\mathbf{M a x}^{3}\end{array}$ & $\begin{array}{l}\mathbf{M i} \\
\mathbf{M i n}^{4}\end{array}$ & $\begin{array}{l}\text { Anisotropy } \\
\text { factor }^{5}\end{array}$ & Dip $^{6}$ & $\begin{array}{l}\text { Dip } \\
\text { direction }\end{array}$ & GSI $^{7}$ \\
\hline Weathered domains & & & & & & & & & \\
\hline GDM1a-w & 3.4 & 45 & 40 & 10 & $\mathrm{n} / \mathrm{a}$ & $\mathrm{n} / \mathrm{a}$ & $\mathrm{n} / \mathrm{a}$ & $\mathrm{n} / \mathrm{a}$ & 70 \\
GDM1b-w & 2.9 & 40 & 40 & 10 & $\mathrm{n} / \mathrm{a}$ & $\mathrm{n} / \mathrm{a}$ & $\mathrm{n} / \mathrm{a}$ & $\mathrm{n} / \mathrm{a}$ & 60 \\
GDM3a-w & 2.8 & 40 & 29 & 10 & 5 & 1.5 & $74^{\circ}$ & $103^{\circ}$ & 50 \\
GDM3b-w & 2.8 & 25 & 18 & 10 & 5 & 1.5 & $74^{\circ}$ & $103^{\circ}$ & 40 \\
\hline Fresh domains & & & & & & & & \\
\hline GDM1a & 3.4 & 69 & 48 & 10 & $\mathrm{n} / \mathrm{a}$ & $\mathrm{n} / \mathrm{a}$ & $\mathrm{n} / \mathrm{a}$ & $\mathrm{n} / \mathrm{a}$ & 80 \\
GDM1b & 2.9 & 53 & 48 & 10 & $\mathrm{n} / \mathrm{a}$ & $\mathrm{n} / \mathrm{a}$ & $\mathrm{n} / \mathrm{a}$ & $\mathrm{n} / \mathrm{a}$ & 70 \\
GDM3a & 2.8 & 53 & 33 & 10 & 5 & 1.5 & $74^{\circ}$ & $103^{\circ}$ & 55 \\
GDM3b & 2.8 & 53 & 18 & 10 & 5 & 1.5 & $74^{\circ}$ & $103^{\circ}$ & 40 \\
\hline
\end{tabular}

1. Young's modulus of intact rock

2. Unconfined compressive strength of intact rock

3. Hoek-Brown mi for intact rock in direction perpendicular to rock fabric

4. Hoek-Brown mi for intact rock in direction perpendicular to rock fabric

5. Ratio of maximum to minimum anisotropic strength

6. Dip and dip direction of rock fabric

7. Geological strength index

Shear strengths of rock mass structures were represented with the Barton-Bandis (BB) criterion. The basic friction angle was determined by HGO from tilt tests on core. Direct shear tests on discontinuities across and along foliation were also assessed. FLAC3D's inherent FISH code was used to define the cohesion and friction angle for each structure according to the stresses acting on the structure, with stresses updated during cycling of the model. Figure 6 shows the BB curves for each joint set. These considered the rougher surfaces of the J1 joints that have been measured by laser scans from which a joint roughness coefficient (JRC) of 9 was determined. JRC $=1.5$ was estimated for the other structure sets. 


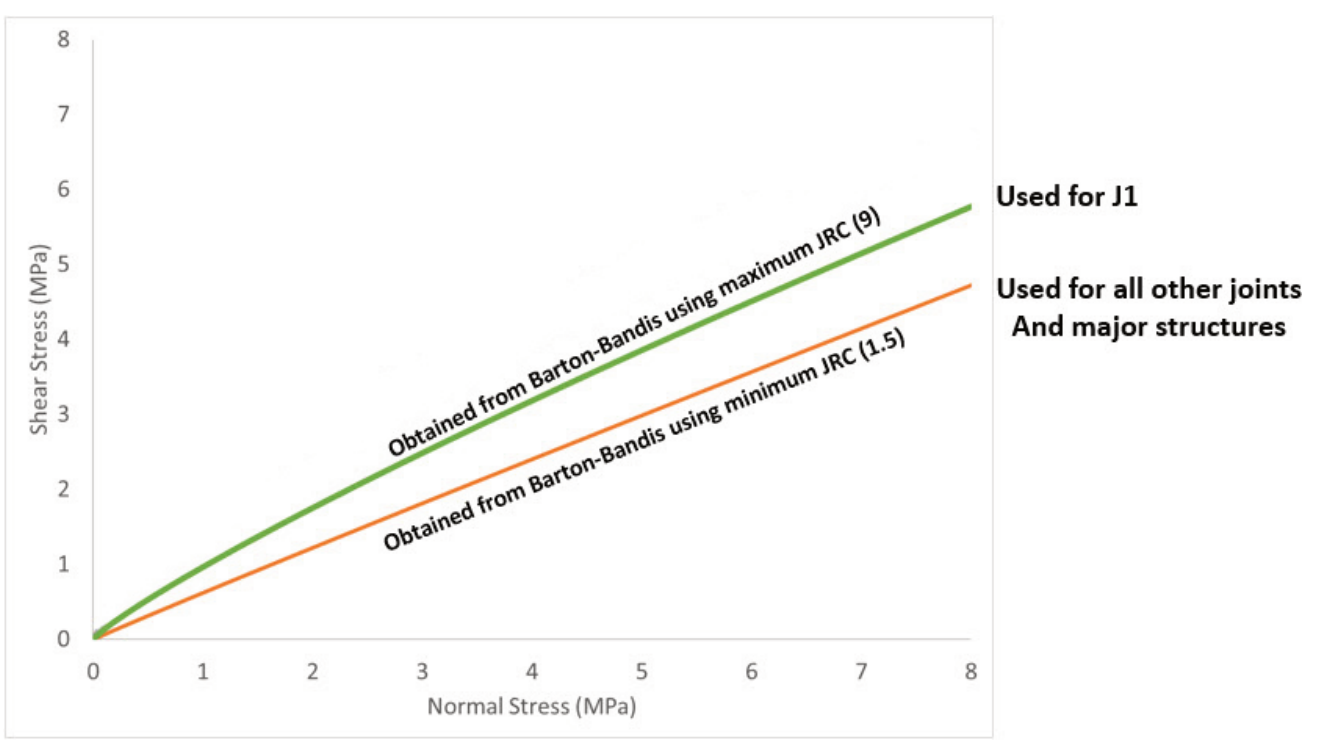

Figure 6 Shear strengths of structures using Barton-Bandis Criterion; basic friction angle $29.5^{\circ}, \mathrm{JCS}=40 \mathrm{MPa}$

\section{$5 \quad$ Modelling outcomes}

\subsection{Slope stability}

Factor of Safety (FoS) with respect to large-scale stability was assessed by applying a shear strength reduction (SSR) technique. In this approach, shear strengths of rock mass and structures were divided by incrementally increasing SSR factors until failure occurs. The FoS is greater than the highest SSR at which the slope is stable and is less than the lowest SSR that results in failure. The FoS is contoured on pit walls and cross-sections for cases where smaller failures have lower FoS, and larger failures have higher FoS. Results of the FoS assessment are shown in Figure 7.

The west wall of the Giant Pit includes a 'bull-nose' or convex corner that extends down to the RL 980, below which is a wider berm and a linear wall. The bull-nose was expected to be less stable as a result of its convex shape and less confinement. The FoS plot shows that the bull-nose has a FoS against deep-seated rock mass failure of between 1.2 and 1.4, and the zone of lowest FoS extends down to the RL 980, below which the FoS increases to greater than 1.4 .

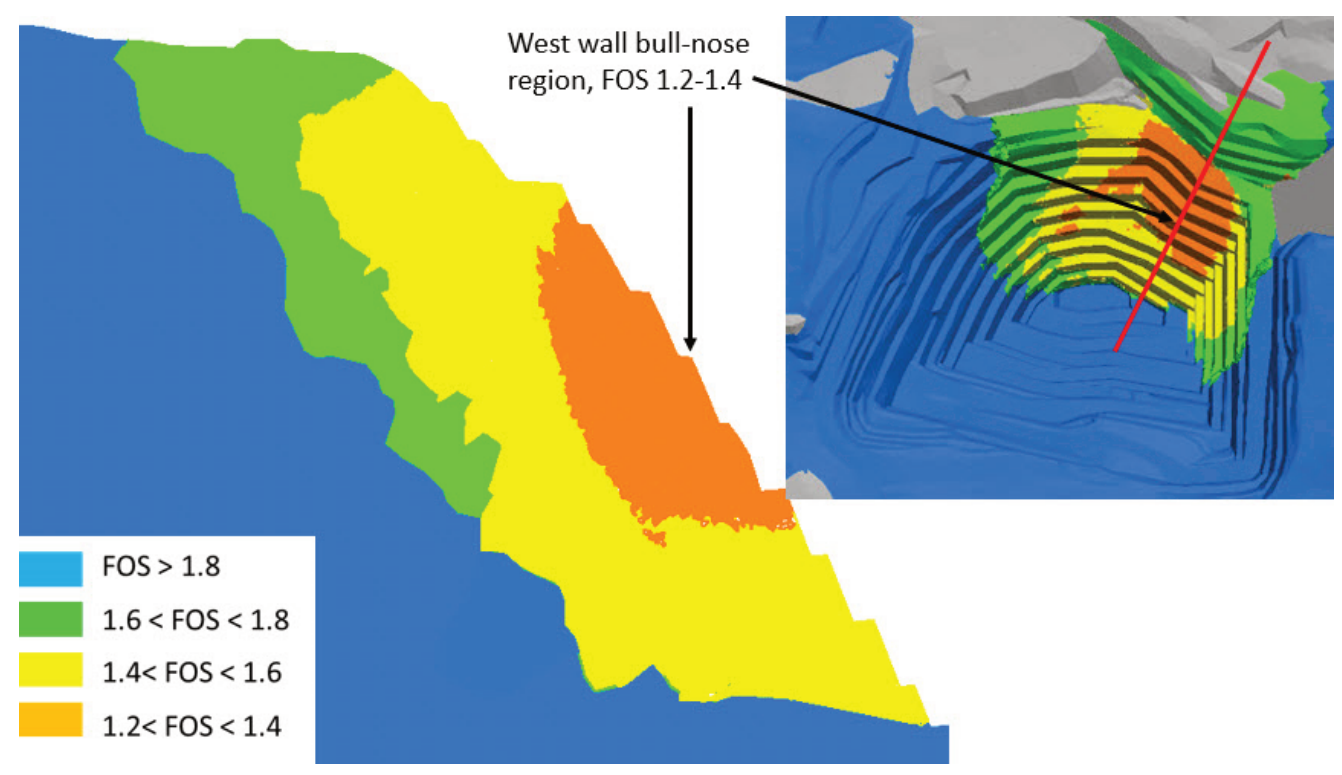

Figure 7 Factor of Safety for the west wall determined using the shear strength reduction method (cross-section looking north, and view looking north-west and down) 
Lorig \& Varona (2000) found that model velocity per model timestep provides an indication of slope stability: velocities below 1e- 6 indicate stability, and velocities greater than 1e- 5 indicate instability. Figure 8 shows modelled velocity and highlights the overall stability of the west wall, with the bull-nose experiencing greater velocity which is well below the instability threshold. Localised greater velocity of crests and batters is indicated, due to structures.

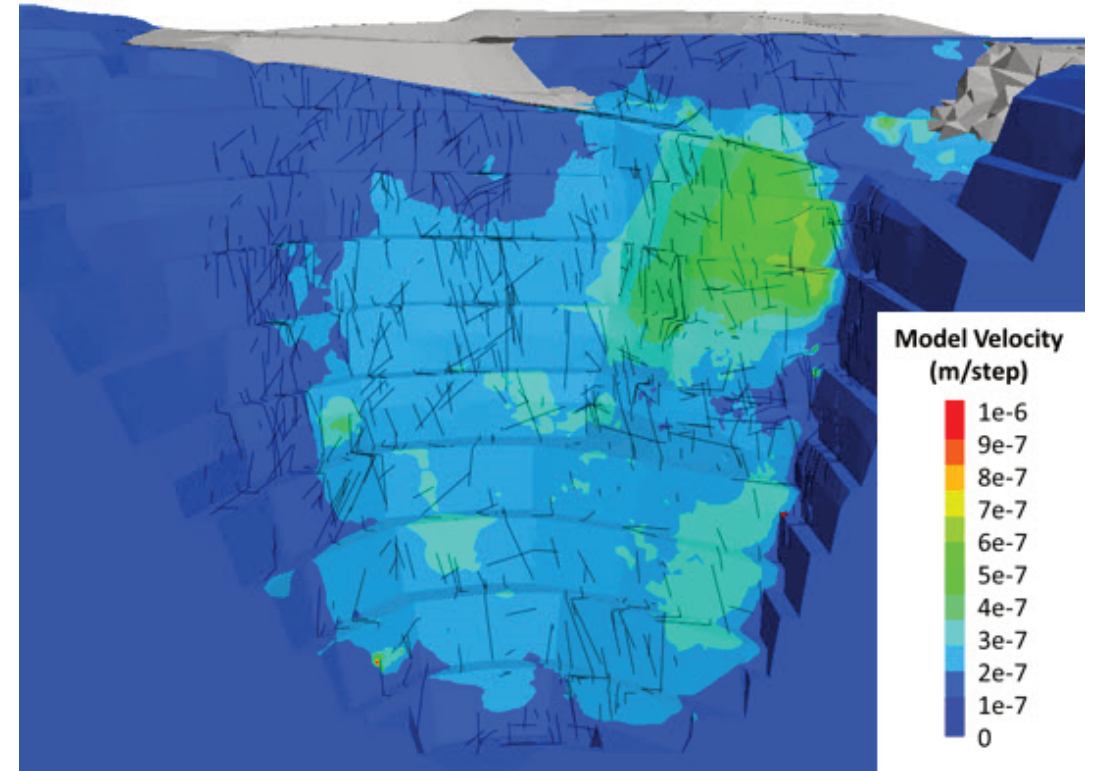

Figure 8 Model velocity for the west wall

\subsection{Mechanism of displacement}

A significant benefit of 3D numerical modelling of this type is its ability to show progressive onset of complex movement mechanisms and potential precursors to failure, even when the design is far from failure. Figure 9 shows the yield state of model zones; i.e. whether they have yielded in shear or tension, and therefore passed their peak strength and become destressed. The yielded and relaxed rock mass would require additional loading before it can develop into a progressive failure. In the west wall bull-nose area, models show shearinitiated yield at the toe, and tension on the upper slope. This indicates the development of an active-passive wedge movement, where an upper block is attempting to slide down along an interface, applying an active load to a lower block in the toe region, which passively resists it.

The cross-sections in Figure 9 show shear-initiated yield along the boundary between GDM3a and GDM3b. Figure $9 \mathrm{~b}$ shows a section through the bull-nose, where the domain boundary is nearer the pit wall. In the south-western wall (Figure 9c), the domain boundary is further from the wall and the mechanism is not as well developed.

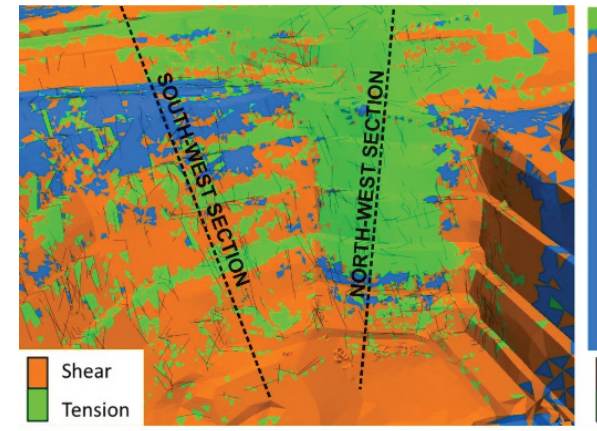

(a) West wall, partly mined

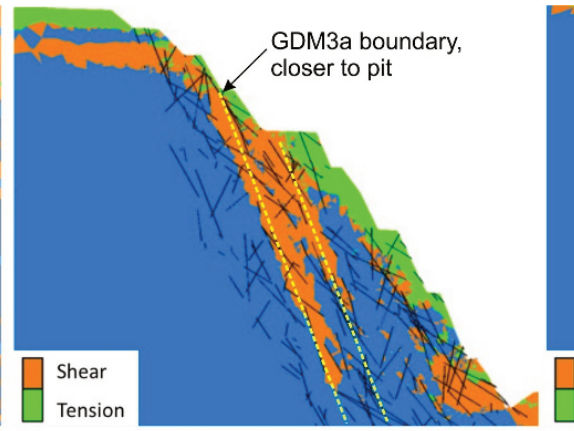

(b) North-west cross-section

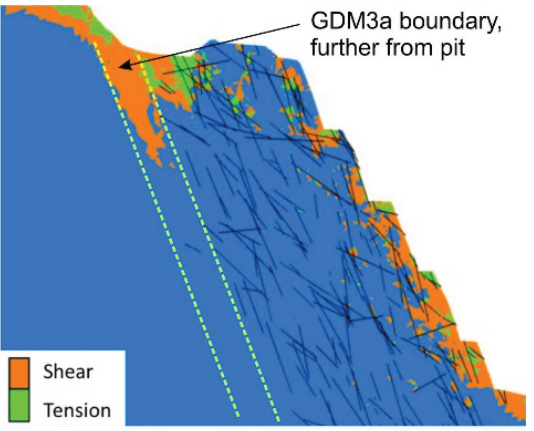

(c) South-west cross-section

Figure 9 Controlling mechanism of displacement, 2018 model, yield state: (a) West wall partly mined, looking north-west; (b) Cross-section through southwest wall; (c) Cross-section through north-west wall 'bull-nose' 
Figure 10a shows an oblique view of the west wall, viewed downward and toward the west-northwest, with contours of displacement, and a horizontal section line. Figure $10 \mathrm{~b}$ shows a horizontal cross-section at the elevation indicated in Figure 10a, contours of displacement, and the boundaries of domain GDM3a. Displacement is greatest where the domain boundary is nearest the wall. Figure 10c shows a horizontal crosssection of the maximum shear strain, and shows the mechanism developing behind the domain interface and along the north-west margin of the west wall.

It is clear from these plots of the mechanism that the region of lower FoS shown in Figure 10 is due not only to the shape of the bull-nose, but also to the presence of the geotechnical domain boundary and the weaker and more ductile biotite schist, nearer the pit wall in the bull-nose region.

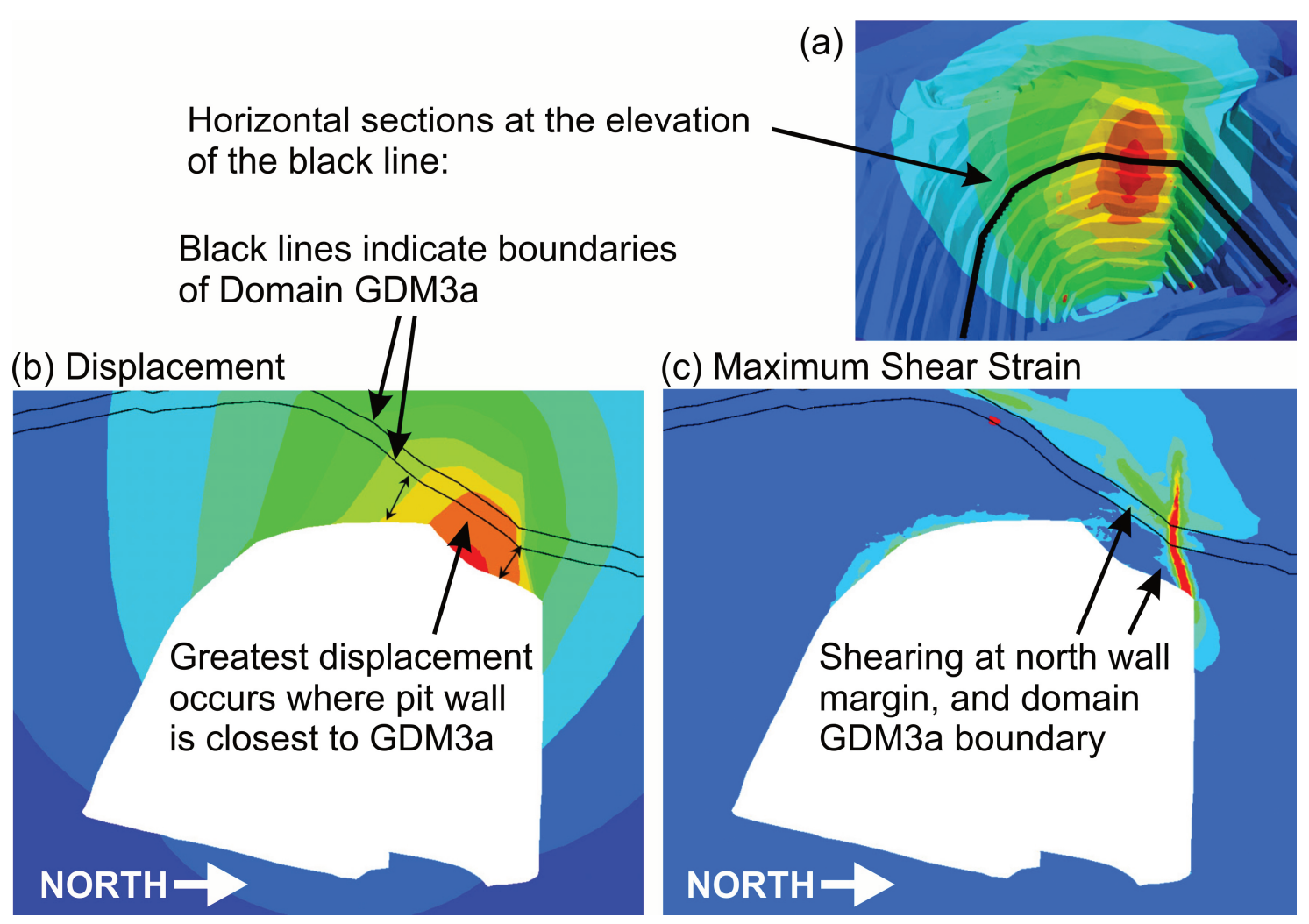

Figure 10 Mechanism of displacement indicated by: (a) Oblique view of west wall showing displacement and horizontal section; (b) Horizontal section showing displacement; (c) Horizontal section showing maximum shear strain

\subsection{Comparison with monitored displacement}

HGO operated a laser scanner for pit slope monitoring during the life of the Giant Pit mining, and this is described in detail by Hutchison \& Chambers (2020). HGO compiled the laser scanning data into a composite image, which is shown in Figure 11a. The FLAC3D model was excavated in a series of increments, representing a simplified mining sequence. The modelled displacement of the west wall over the duration of mining of Giant Pit is shown in Figure 11b. The FLAC3D model predicted displacement of the west wall up to approximately $150 \mathrm{~mm}$, and largely in the bull-nose region above the RL 980 . There is a generally good agreement between the modelled and observed overall regions of displacement, and their magnitudes. The southern side of the bull-nose shows greater apparent displacement in the laser scan data, which is an apparent displacement due to the direction of scanning as shown in Figure 12.

The laser scanner data shows localised zones of displacement that appear to be structurally controlled, which are not as accurately represented on a smaller scale by the FLAC3D modelling because of the representation of the structures as a broad-scale DFN. 


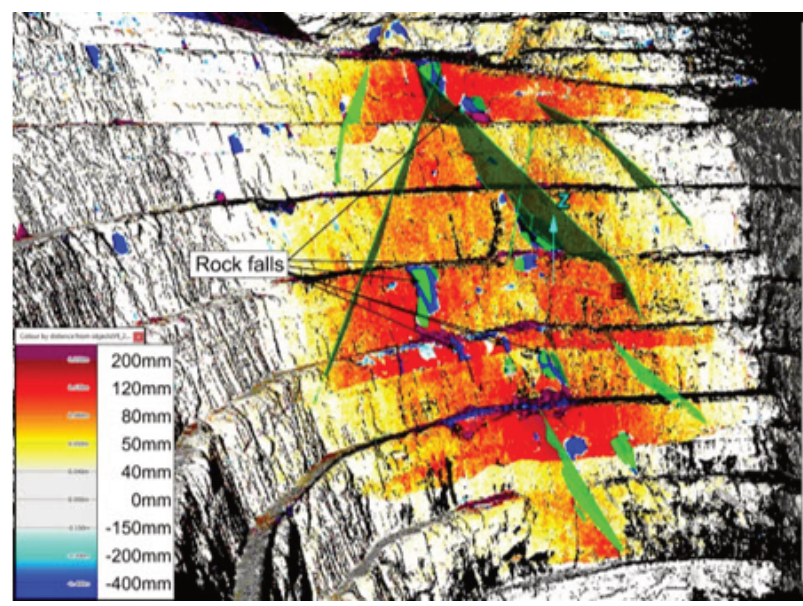

(a)

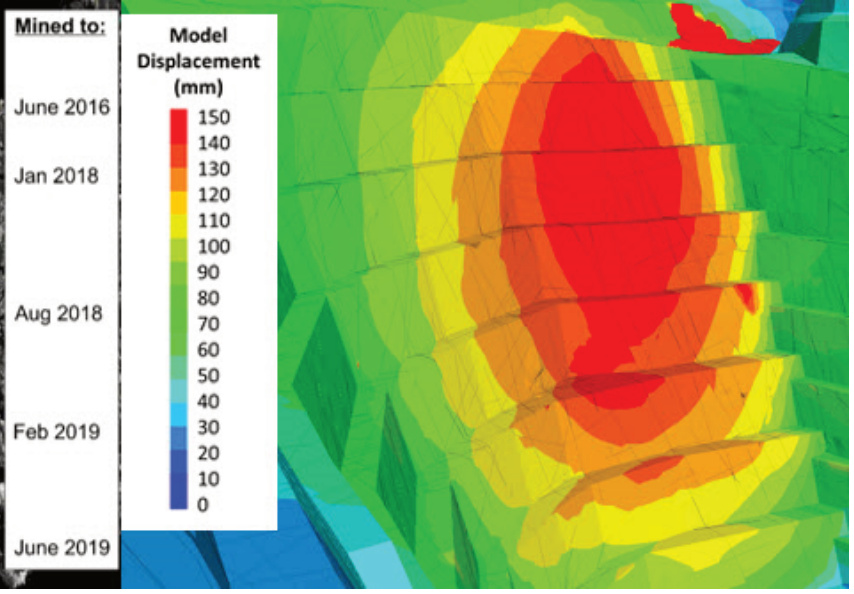

(b)

Figure 11 (a) Compilation of laser scan data from February 2016 to June 2019; (b) Modelled displacement
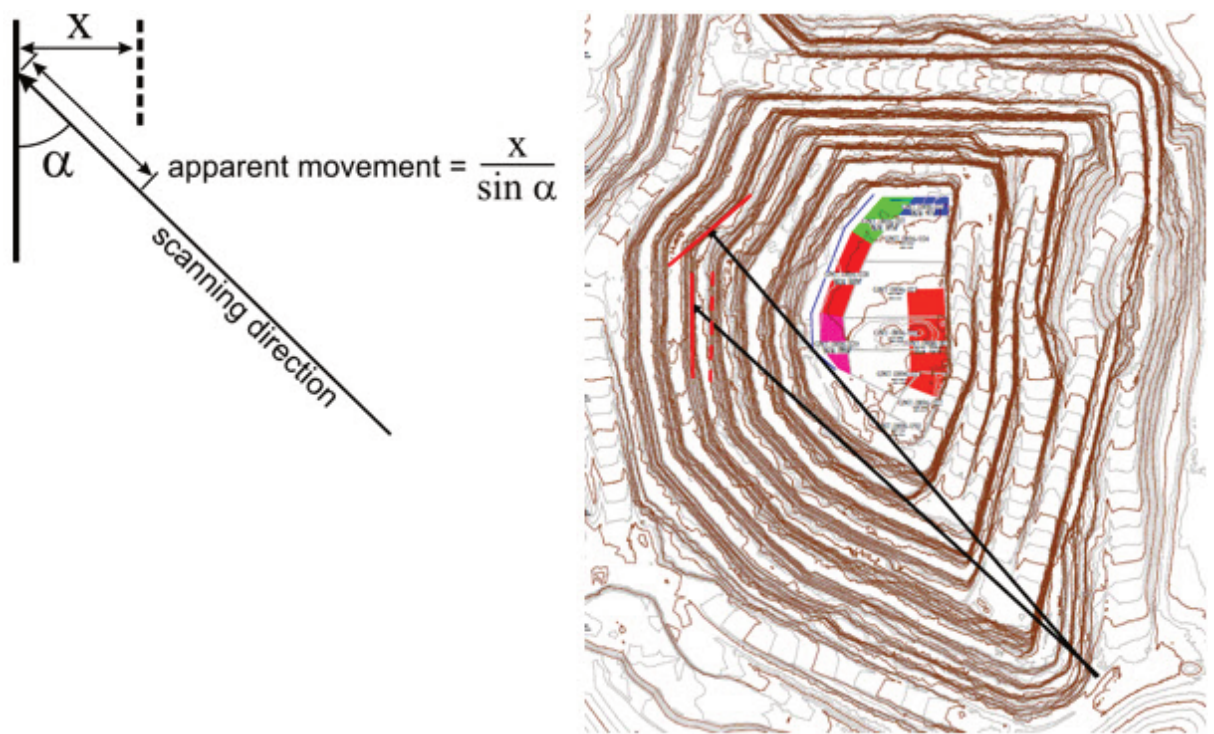

Figure 12 Impact of laser scanning direction on observed apparent displacement

\section{Conclusion}

HGO proposed mining the Giant Pit with steeper batters and overall slope angles, using the experience gained in mining the Kavanagh Pit in the same structural conditions. Hazards due to rockfalls and smaller-scale failures were managed by a combination of ground support and rockfall barrier methods which were proven to be successful in Kavanagh pit. However, the great depth of the Giant Pit, combined with its steepness and confined shape, raised concerns about the possibility of large-scale, deep-seated stress-driven failure. This led to several phases of three-dimensional numerical modelling being conducted to assess the larger-scale stability.

Numerical modelling was completed using FLAC3D, with rock mass structures defined by a DFN, and larger-scale structures defined as explicit surfaces, all built into the finite element mesh along with the pit design and mining stages. This method did not represent every structure at its true scale, as the model would be too complex. Instead, the DFN used scaled structures to represent the relative persistence and spacing at a larger-scale to simulate the larger-scale behaviour of the jointed rock mass. The rock mass between structures was represented by the IUCM (Vakili 2016), including the use of anisotropic parameters to represent foliated rock domains.

Numerical modelling indicated that the Giant Pit design could be achieved with an adequate FoS against larger scale failure. The modelling predicted west wall displacements, due to both the shape of the west wall 
'bull-nose', and a feasible deep-seated mechanism of displacement along an interface between the stronger, more brittle rock that makes up most of the west wall, and the more ductile and foliated rock that lies to the west.

Mining was completed successfully in the Giant Pit in May 2019. Displacements were measured by laser scanning that matched reasonably well on a larger-scale to the modelled displacements, taking account of the differences in the apparent displacement due to the scanning direction. Measured displacements varied in localised areas from those modelled, due to influences of particular structures.

Numerical modelling was used successfully to predict that the proposed Giant Pit design would have an acceptable FoS at an overall slope scale, and that mining-induced stress due to the three-dimensional shape of the pit would not induce stress-driven failure. Successful completion of the Giant Pit essentially verified the modelling prediction, provided a reasonable correlation between modelled and observed displacement, and identified a feasible mechanism of deep-seated displacement. The three-dimensional shape and complex structures could not have been modelled as successfully using more traditional slope stability analysis methods.

\section{Acknowledgement}

The authors are grateful to the management of Hillgrove Resources for their permission to publish this paper.

\section{References}

Alejano, LR \& Alonso, E 2005, 'Considerations of the dilatancy angle in rocks and rock masses', International Journal of Rock Mechanics and Mining Sciences, vol. 42, issue 4, pp. 481-507.

Coffey Mining 2007, Geotechnical assessment and design for Kanmantoo Project Definitive Feasibility Study, Phase 2, Geotechnical Report.

Hutchison, BJ \& Chambers, J 2020, 'Monitoring of structurally controlled deformations at the Kanmantoo copper mine', in PM Dight (ed.) Proceedings of the 2020 International Symposium on Slope Stability in Open Pit Mining and Civil Engineering, Australian Centre for Geomechanics, Perth, pp. 1495-1506.

Hutchison, BJ, Morrison, AT \& Lucas, DS 2020, 'Steep wall mining - experience in the management of rockfall hazards at Kanmantoo copper mine', in PM Dight (ed.), Proceedings of the 2020 International Symposium on Slope Stability in Open Pit Mining and Civil Engineering, Australian Centre for Geomechanics, Perth, pp. 831-848.

Hutchison, BJ, Chambers, J, Gannon, S \& Oko-oboh, D 2017, 'Case study of joint structure and the design and performance of open pit walls at the Kanmantoo Copper Mine', Proceeding of Tenth International Mining Geology Conference, Hobart, pp. 355-364.

Lee, M, Mikula, P, Mollison, L \& Litterbach, J 2008, Stresses in the Australian Continental Tectonic Plate - Variability and Likely Controls, presentation for Australian Earthquake Engineering Society, Ballarat.

Lorig, L \& Varona, P 2013, 'Guidelines for numerical modelling of rock support for mines', in Y Potvin \& B Brady (eds), Proceedings of the Seventh International Symposium on Ground Support in Mining and Underground Construction, Australian Centre for Geomechanics, Perth, pp. 81-105.

Lorig, L \& Varona, P 2000, 'Practical stability analysis using finite different codes', Proceedings of the Slope Stability in Surface Mining Conference, Society for Mining, Metallurgy and Exploration, Littleton, pp. 115-124.

Pando Australia 2012, Hillgrove Resources - Kanmantoo Mine Geotechnical Slope Design Assessment, presentation.

Read, JRL \& Stacey, PF 2009, Guidelines for Open Pit Slope Design, CSIRO, Melbourne.

Rocktest Consulting 2013, Kanmantoo Pit Wall Stability Review and Assessment, report for Hillgrove Resourced Limited.

Sainsbury, DP, Vakili, A, Lucas, DS \& Hutchison, BJ 2016, 'Three-dimensional numerical modelling of potentially structurally controlled failure mechanisms at the Kanmantoo open pit', in PM Dight (ed.), Proceedings of the First Asia Pacific Slope Stability in Mining Conference, Australian Centre for Geomechanics, Perth, pp. 143-156.

Sinclair Knight Merz Pty Ltd (Jacobs) 2014, 'Appendix 3A Groundwater Monitoring and Management Plan', Kanmantoo copper mine, Groundwater Monitoring and Management Plan, Hillgrove Resources Limited, http://www.hillgroveresources.com.au/ media/1/694/ENAUDARW09119_02_Appendices_Vol_1.pdf

Vakili, A, Teet, R, Woo, K, de Veth, A \& Penney, A, 2014a, Understanding Critical Parameters in Stochastic Discrete Fracture Networks, Proceedings of the 1st International Conference on Discrete Fracture Network Engineering, Canadian Rock Mechanics Association.

Vakili, A, Albrecht, J \& Sandy, M 2014b, 'Rock Strength Anisotropy and its Importance in Underground Geotechnical Design', Proceedings of AusRock 2014: Third Australasian Ground Control in Mining Conference, The Australasian Institute of Mining and Metallurgy, Melbourne, pp, 167-180.

Vakili, A 2016, 'An improved unified constitutive model for rock material and guidelines for its application in numerical modelling', Computers and Geotechnics, vol. 80, pp. 261-282. 